\title{
Understanding climate policy integration in the global South through the multiple streams framework
}

\author{
Garcia Hernandez, Alma Lucia; Bolwig, Simon
}

Published in:

Climate and Development

Link to article, DOI:

$10.1080 / 17565529.2020 .1723471$

Publication date:

2021

Document Version

Peer reviewed version

Link back to DTU Orbit

Citation (APA):

Garcia Hernandez, A. L., \& Bolwig, S. (2021). Understanding climate policy integration in the global South through the multiple streams framework. Climate and Development, 13(1), 68-80.

https://doi.org/10.1080/17565529.2020.1723471

\section{General rights}

Copyright and moral rights for the publications made accessible in the public portal are retained by the authors and/or other copyright owners and it is a condition of accessing publications that users recognise and abide by the legal requirements associated with these rights.

- Users may download and print one copy of any publication from the public portal for the purpose of private study or research.

- You may not further distribute the material or use it for any profit-making activity or commercial gain

- You may freely distribute the URL identifying the publication in the public portal

If you believe that this document breaches copyright please contact us providing details, and we will remove access to the work immediately and investigate your claim. 


\title{
Understanding Climate Policy Integration in the Global South through the Multiple Streams Framework
}

\begin{abstract}
Actions needed to mitigate and adapt to climate change have often synergies and trade-offs with other sectoral and sustainable development priorities, and the recent focus on SDGs and sustainable transitions has highlighted the need to consider the integration of climate action into other policy spheres. This process is known as climate policy integration (CPI) or climate mainstreaming. Enhancing its understanding as a public policy making process can provide insights for its operationalization, which becomes relevant considering the implementation of the Nationally Determined Contributions in a sustainable development context.
\end{abstract}

This paper aims to enhance the understanding of the process through which windows of opportunity for CPI are formed, by drawing on elements from the multiple streams framework (MSF) developed by John Kingdon (2014). Using the MSF, this paper analyses grey literature regarding two cases of climate mainstreaming from initiatives implemented by international cooperation organizations. The results show that relevant elements from the MSF, such as, attachment to other high-profile national issues, timing the integration with routine institutional procedures, and the presence of policy entrepreneurs, have been catalysing factors for CPI in the context of such initiatives. However, we can only assess the value of this analytical framework for CPI by testing it systematically through case studies in a variety of contexts.

Keywords: Climate policy integration, climate mainstreaming, policy windows, multiple streams framework, developing countries 


\section{Introduction}

Under the Paris Agreement, the achievement of global climate goals depends largely on nationally determined targets. The Paris Agreement sets an aspirational goal for a global temperature increase to well below $2{ }^{\circ} \mathrm{C}$ (UNFCCC, 2017). Yet it does not provide a blueprint for achieving this objective. Unlike the Kyoto Protocol which legally bounded developed countries to reduce their emissions based on targets agreed as part of the UNFCCC negotiations, the Paris Agreement is based on voluntary commitments by both developed and developing countries on their own domestic emission reduction targets. These voluntary country pledges are denominated Nationally Determined Contributions (NDCs) and have been prepared by national governments in the context of sustainable development and in accordance with national circumstances (UNFCCC, 2015).

Countries expect economic sectors such as energy, agriculture, transport and industry to play a significant role in the achievement of the climate change targets communicated through their NDCs. For example, the Food and Agriculture Organization of the United Nations assessed 162 (I)NDCs (these included 140 'Intended' NDCs) from 189 countries and found that 92\% included agricultural measures as part of their strategy to achieve their mitigation commitments and $69 \%$ as part of their adaptation strategy (Strohmaier, et al., 2016). Similarly, the International Renewable Energy Agency found that 145 out of 190 parties included renewable energy measures to mitigate and adapt to climate change in their NDCs (IRENA, 2017). In the transport sector, the German Agency for International Cooperation showed that countries see transport as a key sector for NDC implementation. From the 163 analysed (I)NDCs, 140 identified transport as an important area for climate action, 105 defined specific mitigation actions and 23 countries mentioned the need for climate change adaptation in the transport sector (Löhr, et al., 2017). Hence, a key premise of this article is that stand-alone climate policies will not suffice to reach the goals of the Paris Agreement; rather the integration of climate change into sector-specific policy domains that frame economic activity and social development will 
be decisive for achieving national and thus global climate goals. This process is known as climate policy integration (CPI) or climate mainstreaming (Nilsson \& Nilsson, 2005; Adelle \& Russel, 2013; Runhaar, et al., 2014).

When addressing CPI, analytically and in practice, it is important to recognize that there can be synergies but also conflicts between climate goals and other dimensions of sustainable development of concern to policy makers, such as food security, energy access, employment and so on. The complex and multifaceted nature of sustainable development is of course not a new idea, and for some time sustainable development and equity concerns have been integral to climate policy and climate research (see, e.g., Fleurbaey et al., 2014). The adoption of the seventeen United Nations sustainable development goals (SDGs) in 2015 has further helped to clarify, frame and operationalise the articulation between climate action and other SDGs (and between other SDGs). More recently, scholars and analysts have developed the concepts of 'sustainable transitions' and 'transformational change' in an attempt to capture not just the complexity and breadth but also the depth of change involved in climate action (and other 'grand challenges' such as biodiversity loss) while at the same time emphasising the long-term nature of such systemic change (e.g., Geels et al., 2016; Sovacool et al., 2020; UNEP, 2019).

An illustrative example of the above points is the articulation of climate action and food security, which is a special concern of many developing countries. In a recent study, Doelman et al. (2019) modelled at global scale the impacts on food security of large-scale land-based mitigation pathways required to meet the Paris targets in a cost-optimal way. They found that land-based mitigation, in the form of afforestation and bio-energy covering some 600 Mha in 2050, results in increased food prices, reduced food availability, and 230 million more people at risk of hunger, if no preventive measures are taken. However, these negative trade-offs can be mitigated through increases in crop yields and ruminant productivity (especially in developing countries), saving land, and through a reduction in 
meat consumption in high- and middle-income countries, saving land as well as GHG emissions. The study and others like it highlight how climate policy can be deeply entangled with sectoral and social (here diet-related health) policies and how this is revealed when the analyst considers trade-offs and co-benefits in a systematic and explicit way. Hence, CPI research must consider these interlinkages and complexities to ensure that climate policies are understood and situated in a broader sustainable development context (Fleurbaey et al., 2014).

Although CPI occurs within national functioning policy systems, the literature on the topic does not leverage enough from public policy theoretical approaches to enable development of analytical frameworks that could enhance its understanding (Ahmad, 2009; Adelle \& Russel, 2013). Especially research on developing countries fails to apply theories of policy making to explain the process of CPI. In an attempt to fill this gap, this paper aims to analyse the usefulness and applicability of a wellestablished approach for public policy making for CPI research with a specific focus on developing countries.

The approach applied in this paper is the multiple streams framework (hereafter MSF) developed by John Kingdon in the book "Agendas, alternatives and public policies" (Kingdon, 2014). This framework has been used to explain changes in climate policy (Brunner, 2008; Keskitalo, et al., 2012; Carter \& Jacobs, 2014; Lorenzoni \& Benson, 2014; Hermansen, 2015), but rarely regarding CPI (Storch \& Winkel, 2013; Uittenbroek, et al., 2014), and mainly with a European focus. Against this background, we pose the following research questions: (i) Is the MSF relevant for explaining policy change towards CPI in a developing country context? (ii) What are its potential limitations for explaining policy change towards CPI in a developing country context? We address these questions by analysing documents from two climate-mainstreaming initiatives implemented by international cooperation organizations in developing countries through the MSF lens. Specifically, we assess the 
applicability and potential contribution to the identification of factors that can enable the changes in sectoral policies that are necessary to achieve national climate change objectives.

The rest of the paper proceeds as follows. Section 2 presents the conceptual and theoretical frameworks guiding this paper. Firstly, following a literature review, the concept of CPI in a global South context is presented. We then introduce the MSF and explore its previous applications in climate policy and CPI studies. Section 3 describes the methods used. Section 4 presents and discusses the results of the document analysis of two climate mainstreaming initiatives, analysing how elements from the MSF, notably timing, problem and solution framing and policy entrepreneurs, relate to the integration of climate change into national development and sectoral policies. The final section presents the conclusions regarding how the MSF contributes to the understanding of CPI and its potential shortcomings.

\section{Towards a conceptual and analytical framework for climate policy integration in a global South context}

A literature review was conducted to learn how scholars and practitioners have defined CPI, and to what extent scholarly literature has used the MSF, to develop explanations for CPI. The first step was to search in the multidisciplinary electronic database Scopus, using the key words "climate policy integration", "climate mainstreaming", and "climate" AND "policy window" in "article title, abstract and keywords". The search was updated on 25 January 2019. The search for the key words "climate policy integration" yielded 36 documents including mainly papers within the European Union (EU) context or with a global perspective; only $16 \%$ of the CPI literature focused on developing countries. The search for the key words "climate mainstreaming" yielded 6 documents while the search for the key words "climate" AND "policy window" yielded 30 documents of which 5 related to developing countries while the rest focused on developed countries, mainly the U.S.A. and Europe. 
After reading through the abstracts of the search results, we selected a first set of papers based on their relevance for this paper (Appendix 1). To assess the relevance of the papers, the following criteria were used: (i) focus on horizontal CPI, i.e., the integration of climate change mitigation and adaptation aims into sectoral public policies at a governmental level (national, regional or local), as opposed to vertical CPI, which refers to integration across different governmental levels; (ii) focus on papers discussing CPI in countries rather than within intergovernmental organizations; and (iii) some book chapters were excluded for practical reasons. The same citations were found repeatedly in the papers selected, pointing towards saturation, i.e., the papers selected were sufficient for the purpose of the literature review, thus it was deemed unnecessary to repeat the searches in other search engine(s).

\subsection{A definition of climate policy integration in developing countries}

Climate mainstreaming and CPI are terms used interchangeably in the literature. Gupta (2010) has argued that mainstreaming goes beyond integration, yet in recent literature (Runhaar, 2016; Scobie, 2016; Wamsler \& Pauleit, 2016; Di Gregorio, et al., 2017; Rietig \& Perkins, 2017; Pilato, et al., 2018) both terms are used interchangeably. The use of either term depends rather on the context; mainstreaming is used more commonly in the international development arena (Ayers, et al., 2014; Ahmad, 2009; Benson, et al., 2014), while CPI originated as a sub-set of the larger environmental policy integration (EPI) approach and is used more generally in a European context (Nilsson \& Nilsson, 2005; Kettner, et al., 2015; Russel, et al., 2018).

Both CPI and EPI are variations of the broader policy integration field, which discusses the integration of inter-sectoral public policies. Scholars have analysed issues such as gender, health or labour markets regarding policy integration. Insights from such policy integration studies can be valuable for CPI research. For comprehensive mappings of the concepts and issues that are part of 
the general policy integration academic debate, see Visseren-Hamakers (2014) and Tosun \& Lang (2017). This paper focuses on the literature on CPI and EPI.

A relevant difference between CPI and EPI literature is the importance placed on the concept of principled priority. Principled priority refers to environmental objectives having priority over sectoral, societal and economic objectives when there are potential trade-offs or conflicts (Lafferty \& Hovden, 2003). There are both normative and positive dimensions of principled priority. While EPI scholars support a normative dimension giving the environment principled priority vis-á-vis other sectoral objectives (Lafferty \& Hovden, 2003; Dupont \& Oberthur, 2012; Adelle \& Russel, 2013), the CPI literature focuses on synergies and co-benefits between climate change and sustainable development objectives (Adelle \& Russel, 2013; Rietig, 2013; Benson, et al., 2014; Di Gregorio, et al., 2017). This may be explained by a growing awareness that climate change action is not always compatible with other concerns, as mentioned in the introduction. For example, there can be negative environmental or social impacts of climate-friendly sources of energy such as nuclear, biomass and hydropower (Rietig, 2013; Humalisto, 2015; Persson, et al., 2016). Furthermore, some climate change measures could carry trade-offs for economic development, which in turn may hinder important priorities for developing countries such as poverty eradication or food security (Beg, et al., 2002). Thus, giving climate objectives principled priority over other environmental, economic and social objectives may be perceived to compromise overall sustainable development goals.

Regarding the positive dimension of principled priority (i.e. how principled priority has worked in practice), EPI scholars argue that EPI implementation in the EU has failed to give principled priority to environmental objectives over economic ones (Adelle \& Russel, 2013). In practice, economic, social and environmental concerns that seem compatible at a more generic level imply inevitable trade-offs. When these conflicts among goals are confronted, objectives of economic policy usually 
prevail due to short-term political interests (Lafferty \& Hovden, 2003; Dalal-Clayton \& Bass, 2009; Runhaar, et al,, 2014; Storbjörk, et al., 2009). In the case of CPI, scholars have focused mostly on pursuing synergies and co-benefits, stressing the importance of avoiding trade-offs between climate and other objectives (Adelle \& Russel, 2013; Ayers, et al., 2014; Steuner \& Clar, 2015). However, some CPI scholars have stressed that some trade-offs are unavoidable and need to be dealt with. Yet, in the absence of strong political priority to climate objectives over economic or sectoral ones the achievement of climate objectives is limited (Kettner, et al., 2015; Kok \& de Coninck, 2007).

There are also important differences between strands of literature focused on industrialized and developing countries. The latter strand emphasizes the integration of climate change into development planning. Furthermore, most of the CPI literature on countries from the global South is discussed from a development cooperation perspective (Ayers, et al., 2014; Conway \& Schipper, 2011; Benson, et al., 2014; Butler, et al., 2016; Di Gregorio, et al., 2017; Saito, 2013). This can be explained by the close linkages between development and climate change. Development agencies recognize climate change impacts as a threat to their efforts to promote economic development and poverty reduction, while climate-related projects in turn may be ineffective if economic growth causes an increase in GHG emissions. They therefore consider it to be a more effective and efficient use of resources to address both issues in an integrated way (Gupta, 2010; Ayers, et al., 2014).

We also observe differences in terms of which climate change aspect, mitigation or adaptation, needs to be mainstreamed when comparing literature on countries from the global North and the global South. The studies of CPI in a global South context emphasize the adaptation dimension of climate change compared to early literature on CPI from industrialised countries. We identify two main reasons for this difference. First, while the impacts of climate change affect all countries, the capacity to adapt to climate-related hazards is determined by factors related to poverty. Poor people in the global South thus experience a greater and more direct effect on their livelihoods and therefore need 
more support for adaptation (Ayers, et al., 2014; Olsson, et al., 2014). Development cooperation has therefore emphasized the mainstreaming of climate adaptation from the rationale that increasing the capacity of vulnerable groups to deal with climate impacts and risks is central for the achievement of other development goals (Olhoff \& Schaer, 2009). Second, the limited emphasis on the mitigation dimension in CPI literature on developing countries can be explained by the "common but differentiated responsibilities and respective capabilities" principle that the UNFCCC signatories have agreed to, according to which the developed countries should take lead in combating climate change (UNFCCC, 2002; Fleurbaey, et al., 2014).

Yet in the recent Paris Agreement, both developed and developing countries have agreed to reduce greenhouse gas emissions as soon as possible. For developing countries especially, which are still investing heavily in building urban and industrial infrastructures, mitigation actions should also contribute to avoiding being locked into carbon intensive development pathways (Denton, et al., 2014; Fleurbaey, et al., 2014). These considerations imply that CPI must account for the interactions between mitigation, adaptation and sustainable development to avoid maladaptation or mitigation that hinders adaptation or broader development efforts.

CPI is an emerging research topic and the definitions of CPI found in the literature vary. Some scholars define it as a policy output while others conceptualize it more as a policy process (see Appendix 2). Nonetheless, all definitions refer to CPI as the integration of climate change into other non-climate policy areas. In this article, CPI is considered as the integration of climate change mitigation and adaptation objectives into relevant sectoral and development policies. We turn now to discuss a positive approach to CPI to better understand how it takes place in practice as part of national policy making processes. 


\subsection{Understanding climate policy integration from a multiple streams framework perspective}

We argue here that applying a public policy-making perspective will improve the analysis of CPI in important ways. According to Adelle and Russell (2013), the CPI literature pays less attention to how to undertake CPI compared to the EPI literature. The latter relies heavily on public policy and administration studies to shed light on the processes and instruments for its operationalization. This is problematic because CPI does not happen in isolation but occurs within national policy systems (Ahmad, 2009). Thus, it is relevant to review public policy theories and critically assess how they can contribute to analysing the process through which the policy changes that CPI entail are brought about and the different factors that may trigger such changes. On this background, this paper studies CPI from a public policy making perspective with a focus on the early stages of the public policy making process when policy is more shapable and integration can be easier to achieve (Schout \& Jordan, 2008; Adelle \& Russel, 2013; Vasileiadou \& Tuinstra, 2013). CPI as a process of policy change has been previously discussed in the CPI and EPI literatures (Nilsson \& Persson, 2003; Nilsson \& Nilsson, 2005; Rietig \& Perkins, 2017). Yet, as Runhaar et al. (2014, p. 242) suggest, the application to CPI research of concepts such as "discourse, interests, power, policy entrepreneurs, competing networks, windows of opportunity, etc." from theories of policy change and policy controversies remains unexplored. Furthermore, scholars have analysed CPI in the global South mainly from a development cooperation perspective as opposed to from a public policy perspective.

In view of this, we hypothesize that concepts and models from the public policy discipline can contribute to improving the understanding of how public policies change to address climate change. As Howlett et al. (2016) suggest, there is no a priori reason why any of the current policy-making frameworks (e.g. Advocacy Coalition Framework, Policy Cycle Model, Punctuated Equilibrium and MSF) should be adopted over any other as they all attempt to explain policymaking through variations 
of subsystem or network theories. We chose to utilize the MSF because we specifically want to assess the usefulness of the concept of windows of opportunity for understanding CPI. We argue that the MSF has potential to explain CPI because it considers that policy solutions can be framed as solutions to address different problems. This is relevant to CPI because some solutions to climate change mitigation and adaptation have co-benefits for other sectors and therefore can be framed as solutions to other high-profile issues. In the discussion and conclusions sections we discuss the usefulness of this framework as well its limitations for CPI research.

The following paragraphs introduce the MSF and its most important features.

\section{The multiple streams framework}

The MSF considers policy making as a set of processes: (i) agenda-setting, (ii) alternative specification, (iii) authoritative choice among specified alternatives, and (iv) implementation of the decision (Kingdon, 2014, pp. 2-3), and focuses on the first two processes, with the aim of explaining why some issues become relevant on the agenda and why some proposals to address such issues are preferred over others. The MSF suggests that the processes through which issues and alternatives become relevant are of three kinds: problems, policies and politics. Thus, either problem recognition, generation of policy proposals, and political events, can catalyse or constrain policy change. Following the 'streams' metaphor, each of these processes develop independently from one another, each one has its own logic and usually a different set of actors; however, at some critical junctures they are joined, opening a window of opportunity for policy change. The problem stream can be influenced by crises or events, changes in relevant indicators, feedback from current programs, or by comparing performance with, for example, another country. In parallel, the political stream can be determined by changes of administration or turnover of key personnel among other factors. Finally, 
gradual accumulation of knowledge and perspectives among specialists or the development of new technology can influence the policy stream (Kingdon, 2014).

Kingdon also compares the policy stream to a "primeval soup" in which ideas and proposals are floating around policy communities and are continuously confronting each other, recombining with one another and getting refined. The ideas that survive are typically technically and budgetary feasible, fit with dominant values of the policy community members and the current national mood, are publicly acceptable and have politicians' receptivity. These views keep floating around in or near government searching for problems to attach themselves to, and for political events that increase their likelihood of adoption (Kingdon, 2014). Policy windows can be predictable or unpredictable. Table 1 shows the categorization of policy windows suggested by Howlett (1998) depending on the elements that trigger them.

\section{Table 1. Types of policy windows and potential openers}

When a window opens, advocates of proposals sense this opportunity and take advantage of it by coupling the streams. These advocates of proposals, or policy entrepreneurs, are one of the key components of the policy windows approach. Policy entrepreneurs are actors within or outside government that are willing to invest resources and play a central role, not only in advocating their proposals in their policy stream but also in coupling the streams at the window by hooking solutions to problems, proposals to political momentum, and political events to policy problems. Policy entrepreneurs often have the following attributes: political connections, negotiating skills, a claim to a hearing (either through expertise, ability to speak for others, or being in an authoritative decisionmaking position), and they are persistent (Kingdon, 2014). 
Figure 1 summarizes the different streams, the factors affecting each of them, the conditions under which policy proposals survive and the activities carried out by policy entrepreneurs according to the MSF.

Figure 1. Relevant elements of the multiple streams' framework. Based on (Kingdon, 2014) Applications of the multiple streams framework in studies of climate policy and climate policy integration

In recent years, scholars have used the MSF to explain changes related to climate policy in the United Kingdom (UK) and Germany. For example, Brunner (2008, p. 501) employed the MSF to analyse the change from overgenerous grandfathering to tight caps and auctioning within the German emissions trading regime in the first half of 2007. Carter and Jacobs (2014, p. 125) combined the MSF with Baumgartner and Jones' punctuated equilibrium model to explain the transformation of UK climate change and energy policy under the Labour Government between 2006 and 2010. Similarly, Lorenzoni and Benson (2014) applied the MSF combined with discursive institutionalism to study the process that led to the UK Climate Change Act 2008. In all three studies, the MSF proved useful for understanding relevant aspects of changes in climate policy. However, all studies also identified limitations of the MSF in terms of explaining changes in climate policy. For example, Brunner (2008) found that the MSF does not consider sufficiently the influence of multi-level governance structures, i.e., the influence of the EU in the political stream, and can underestimate the effect of learning processes and networks of experts in the policy stream. Another limitation found by Carter and Jacobs (2014) is that the MSF can overlook the significant policy entrepreneurship role that government ministers can play and the role of party competition in opening and sustaining policy windows, especially when analysing policy change in countries with parliamentary systems. Furthermore, Lorenzoni and Benson (2014) found that the MSF does not explain sufficiently the role of ideas in 
promoting institutional change and thus used discursive institutionalism to complement the MSF and generate new insights about the conditions under which change can occur. These studies demonstrate that the MSF captures important aspects of policy change, but that it is important to amend and combine this framework with other explanatory approaches, depending on the case of study, to understand fully the process of policy change.

Storch and Winkel (2013) and Uittenbroek, et al. (2014) have applied the MSF to improve the understanding of CPI. Storch and Winkel (2013) used the MSF to analyse the integration of forest policy measures into climate change policy in two German States, Bavaria and North Rhine Westphalia. Similarly, Uittenbroek et al (2014) applied the MSF to improve the understanding of political commitment to climate change in two Dutch municipalities, which took different approaches to climate change: Amsterdam approached it through CPI and Rotterdam through dedicated climate policy. Both articles highlight the role of policy entrepreneurs in leveraging policy windows. As Storch and Winkel (2013) show, the extent of the integration of forest policy measures into climate policy depended strongly on policy entrepreneurs from the forest sector who, supported by forest science, were able to substantiate the need for climate change adaptation measures in the forest sector. The studies also show that policy windows were generated in different spheres. In Amsterdam, entrepreneurs used policy windows that opened in the spatial planning and water departments to integrate adaptation into such sectors. In Bavaria, forest policy entrepreneurs exploited policy windows opened by climate change being dominant on the political agenda to push forward forest policy measures. Thus, a climate change action can be framed as an added value to sectoral priorities and sectoral priorities can be framed as climate solutions, depending on where the policy window opens. This shows that spill over policy windows for CPI can work both ways.

Other works on CPI have addressed elements relevant for the MSF without using the framework in a comprehensive way. One important element is policy entrepreneurs, which, according to the MSF, 
are essential for identifying and taking advantage of policy windows. Rietig and Perkins (2017) studied the integration of climate finance into the EU budget and found that policy entrepreneurs from the Climate EU office played a key role in ensuring that $20 \%$ of the overall EU 2014-2020 budget was allocated to climate action. In this case, we may consider the budget renewal process as a predictable, routine political window, following the categorization of policy windows by Howlett (1998) (Table 1). This political window was identified and exploited by the policy entrepreneurs from the Climate EU office.

Framing has also often been explored in the CPI literature. This element is important for coupling Kingdon's three streams. In order to "hook solutions to problems, proposals to political momentum and political events to policy problems" (Kingdon, 2014, p. 182), policy entrepreneurs engage in a process of refurbishing their solutions or proposals by framing them differently to fit better to the problem that has come to attention, so they can sneak into the spotlight, as Greer (2015) suggests. Likewise, the framing of the problem, or how it is defined, is relevant and can also be affected by policy entrepreneurs (Kingdon, 2014). Problem framing refers here to the process of discursive construction through which conditions become problems that are apprehensible and amenable to a solution in the first place. Regarding policy integration, policy frames are very relevant since they can "act as policy glue binding issues and actors together" (Bocquillon, 2015, p. 341). In this regard, a strand of the CPI literature also suggests that a more positive framing of climate change solutions, in terms of its co-benefits for economic growth and sectoral priorities such as energy security or job creation, can make CPI a more attractive issue that fits with prevailing frames and thus can catalyse it (Mickwitz, et al., 2009; Adelle \& Russel, 2013; Runhaar, et al., 2014).

Although some climate policy and climate policy-integration studies have applied the MSF, its use to explain climate policy integration in developing countries has been negligible. An exception is Butler et al. (2016), who analysed a four-year governance experiment in Indonesia aimed at the 
integration of climate adaptation into development planning. They used the MSF as part of their theoretical framework and found an absence of policy windows in the experiment, which they attributed to "ineffective and insufficient time for political engagement, and the fluid institutional environment caused by a national decentralization policy" (Butler, et al., 2016, pp. 1,14). They further argue that the integration of adaptation into development planning "...requires the long-term support of transdisciplinary teams, who can act as leaders, brokers, facilitators and policy entrepreneurs to exploit policy windows when they eventuate" (ibid). However, the study does not provide information on potential window openers for CPI, suggesting a potential for further application of the MSF for the analysis of CPI in developing countries.

\section{Methodology}

We used document analysis as a qualitative research method to make a first appraisal of the appropriateness of the MSF to study CPI in developing countries. We selected as data sources publicly available progress reports and documented lessons learnt from two climate-mainstreaming initiatives: (i) the Poverty-Environment Initiative (PEI) of the United Nations Development Programme and the United Nations Environment Programme; and (ii) the Mainstreaming Climate Change into National Development Planning initiative launched by the Global Climate Change Alliance (GCCA) of the European Commission. We selected these two initiatives because they aim to support the integration of climate change into national development and sectorial policies. Although international organizations lead the initiatives, they aim at influencing CPI within national policy systems in the countries of implementation. In the conclusion, we will discuss the potential role of this type of organization in the different streams of the MSF since the MSF was developed essentially to explain policy making by national actors. 
The PEI initiative was launched in 2005 to "help countries to integrate poverty-environment linkages into national and sub-national development planning, from policymaking to budgeting, implementation and monitoring" (UNDP-UNEP, 2015). The PEI has been implemented in 28 countries in Africa, Asia, Europe Commonwealth of Independent States, and Latin America (Benson, et al., 2014). It has a special focus on climate change adaptation and development. It acknowledges that adaptation policies must be formulated as part of broader policies for development and therefore aims to mainstream the links between poverty reduction and climate change adaptation into national development planning (UNDP-UNEP, 2009).

The GCCA supports climate mainstreaming programs in seventeen countries and in four regions, namely Western Africa, Eastern and Southern Africa, the Lower Mekong Basin and the Pacific. The GCCA goal is to "support the systematic integration of climate change considerations into development planning, from policymaking and budgeting to implementation and monitoring" (European Commission, 2012c). The GCCA shares with the PEI an emphasis on adaptation, but it further considers mitigation measures, such as reducing emissions from deforestation and forest degradation and enhancing participation in the global carbon market (European Commission, 2012c).

The document analysis involved the examination and interpretation of documents in a systematic way and yielded data in the form of excerpts or quotations. The content analysis of the documents entailed a review using the software Atlas $t i$, in which relevant passages of text were identified and coded. We used hypothesis coding, which is a deductive approach based on the application of a predetermined list of codes onto qualitative data. This method is particularly useful to assess hypotheses relative to causes or explanations in the data (Saldana, 2009). We generated a predetermined list of 25 codes based on relevant factors derived from the MSF, e.g., focusing events, high-profile issues, politicaladministrative turnovers, persistency, etc. The codes were clustered into four substantive categories: the problem stream, the policy stream, the politics stream, and policy entrepreneurs. The selected 
documents were examined, and when passages of text relevant to any of the predetermined codes were identified, they were highlighted and coded accordingly using the software Atlas ti. Appendix 3 presents the list of documents analysed and the codes used for the analysis and table 2 presents examples of the coded data in the form of quotations.

\section{Results}

Through the document analysis we were able to identify factors at the three streams influencing the emergence of windows of opportunity for CPI in developing countries. Our study hereby goes further than the one by Butler et al. (2016) referenced earlier, which found no potential window openers for CPI. Below we discuss factors related to each stream in turn. We draw on Table 2 that assesses the applicability of the MSF for CPI in countries and provides quotes from the analysed reports and how they relate to the relevant factors of each stream of the MSF.

Table 2. Analysis of two climate mainstreaming initiatives using elements from the policy windows

\section{framework}

\section{The problem stream}

Reports from both initiatives highlighted the relevance of certain factors influencing the problem stream (Table 2). The reports mentioned crisis or focusing events as relevant factors for the emergence of entry points for climate mainstreaming. For example, the PEI in Cambodia identified a flood that occurred in 2000 and caused large economic damages as a focusing event in the problem stream that facilitated the prioritization of coastal zone, disaster management and other adaptation measures into the national Poverty Reduction Strategy Paper in 2003 (UNDP-UNEP, 2011, p. 52)

Another identified relevant factor in both initiatives was the use of indicators. Kingdon (2014) suggests that attention to problems can be driven by indicators, which can be routinely monitored, 
such as the monitoring of federal expenditures or studies conducted on a particular problem at a given point in time. In this sense, both the PEI and GCCA highlight the use of cost-benefit studies, expenditure reviews and studies that quantify the value of natural and social capital to better communicate the magnitude of the problem to decision-makers. In Mozambique, for example, the GCCA identified that environmental and climate change issues rose on the political agenda, based on evidence of impacts on development, and on publications such as the 'Study on the Impact of Climate Change on Disaster Risk in Mozambique' (INGC, 2009). This led the government to support the mainstreaming of adaptation measures and environmental sustainability in economic planning (European Commission, 2012b, p. 14).

Developing countries typically have limited capacity to monitor indicators. Both initiatives highlighted this weakness, and both had a focus on strengthening monitoring systems. For example, the PEI in Mauritania provided technical advice to the Ministry of Environment to establish a sustainable development database. The database has information on poverty-environment indicators, such as access to clean energy, water and sanitation and the state of the environment, and was created to inform sector policy and planning processes in support of sustainable development (UNDP-UNEP, 2016a, p. 18). The GCCA reports also emphasize the importance of producing credible evidence of the loss and damage induced by climate change, by using economic analysis to make the case for action with the aim of raising climate change and disaster risk reduction high on the political agenda (European Commission, 2013a, p. 14).

Finally, both initiatives show the potential for centring mainstreaming on other high-profile issues at national level. Spill over windows in the problems stream were leveraged by turning climate change mitigation or adaptation measures into solutions to other high-profile issues, such as energy security, waste management, livelihood diversification, jobs creation, natural resources extraction, or high- 
cost food imports. Examples from the PEI include mining in Mongolia and the Philippines, disaster risk reduction in Bangladesh and Nepal, and food security in some African countries (UNDP-UNEP, 2017b, p. 15). Another example of this from the GCCA was found in Mauritius and Seychelles. Here, national development strategies include objectives in terms of reduced dependence on imported fuels, providing a rationale for mainstreaming climate mitigation into the energy sector through increased use of renewable energy and energy efficiency (European Commission, 2012b, p. 18). These findings are in line with the strand of CPI literature that suggests framing climate change solutions in terms of its economic and sectoral spill over effects (Mickwitz et al., 2009; Adelle \& Russel, 2013; Runhaar et al., 2014).

\section{The policy stream}

The MSF emphasizes that policy proposals must have the receptivity of politicians and the public in general. Both the GCCA and PEI highlight the need to build awareness and soften-up the system before moving to mainstreaming implementation (Table 2). For example, the GCCA mentions that "outreach and involvement of a wide range of stakeholders are also critical to generate public support: buy-in should be sought not just from political leaders and central government, but also from local government and non-state actors" (European Commission, 2013b, p. 15). Similarly, the PEI points at building messages and awareness raising within a broad range of actors within and outside government. These actors include heads of state's office, political parties, legislators, finance and planning bodies, environmental institutions, sector and subnational bodies, the national statistics office, civil society, academia, industry, the media, and the public (UNDP-UNEP, 2017b, p. 31). Both initiatives aimed at softening-up the system and building acceptance for their proposals by framing them through an economic lens or in terms of the potential impacts of climate change on development. Both initiatives also stress the need for feasibility and cost-benefit analysis to enhance the accumulation of knowledge and evidence to make sure that the final proposals have technical and 
budgetary feasibility for implementation. In a developing country context, budgetary feasibility may imply the need for access to climate finance from international organizations and donors.

\section{The political stream}

In terms of the factors that influence the political stream, both initiatives strongly advocate for the identification and use of routine windows that open due to scheduled institutional procedures. This type of window was leveraged during the implementation of both initiatives. In countries such as Bhutan, Cambodia or Samoa, the GCCA aimed to synchronize its activities with national processes of multi-year development or sectoral plans. Another factor relevant to the political stream is politicaladministrative turnovers, which the initiatives reported as relevant. For example, the PEI in Malawi highlighted that due to a presidential intervention, the country's National Adaptation Programme of Action gained relevance after three years of its publication, facilitating the rise of adaptation in the agendas of sectoral ministries (UNDP-UNEP, 2011, p. 34).

\section{The role of policy entrepreneurs}

Both the PEI and the GCCA initiatives emphasize the important role of champions (or policy entrepreneurs) in the mainstreaming process and the need for these champions to be in an authoritative decision-making position (Table 2). The PEI report also observes that it is a weakness that champions are not engaged in the process for very long and that finding replacements was challenging. This finding is in line with Kingdon's emphasis on the quality of "persistency" for policy entrepreneurs, which seems to be lacking in the case of the PEI initiative. This issue was also identified in the study of CPI in Indonesia (Butler, et al., 2016), which found that policy entrepreneurs needed longer-term support to be able to exploit policy windows. 


\section{Discussion and conclusion}

Research on CPI with a focus on developing countries is scarce and relate insufficiently to studies of public policy and public administration. At the same time, developing countries are facing challenges in implementing their NDCs. One of these challenges is the integration of climate change objectives into sectoral and development policies, a process that can entail policy change. There is therefore a need to draw on elements of policy change frameworks to enhance the understanding of this process, which in turn can help operationalize CPI. Another important challenge in a developing country context is the need to address the interlinkages between climate and sectoral and social policies by considering their co-benefits and trade-offs. In this regard, the rationale behind the selected framework, the MSF, is based on the argument that policy solutions can be framed as solutions to address different problems, depending on the problems that are high on the agenda at a certain point in time. Thus, when applying the MSF to CPI, the focus is on the solutions to climate change mitigation and adaptation that have co-benefits for other sectors and therefore can be framed as solutions to other high-profile issues. This is aligned with the focus of CPI literature on the synergies and co-benefits between climate change and sustainable development objectives. Nevertheless, as further discussed in this section, we acknowledge the limitations of the MSF to address trade-offs between climate and other development and sectoral objectives.

The aim of this study was to review the MSF and to assess its usefulness in explaining the formation of windows of opportunity for CPI in a developing country context. We found that elements of the MSF from the three streams: problems, policy and politics were relevant for catalysing CPI in both the PEI and the GCCA initiatives. In the problem stream, spill over and random windows were opened by attaching climate change to other high-profile issues, by using indicators and by focusing events. In the political stream, routine windows opened through scheduled institutional procedures and both initiatives leveraged political-administrative turnovers during their implementation. Regarding the 
policy stream, the conditions under which, according to the MSF, policy proposals survive were present in both initiatives, namely: technical feasibility, budgetary workability, public acceptability, politician's receptivity, and a fit with dominant values of policy community members.

We also found potential shortcomings of the MSF to explain CPI. Firstly, ideas play a central role in the MSF, whereas the most common focus of political science is power and interests. Ideas-based frameworks, like the MSF, do not deny that politics involve power struggles, nor do they suggest that ideas are the only factor influencing policy change. They rather propose that what affects policy is the interactions or relationships between ideas, interests and institutions (Campbell, 1998; Béland, 2009; Hall, 1993). Regarding interests, the MSF suggests that policy proposals must fit with dominant values of policy community members and have the receptivity of politicians for decision-makers to consider them. For CPI, although there might be abundant climate action options that are synergetic with other goals, some ambitious measures might challenge dominant values and key interests of other sectors, for example regarding food security.

Hence, the MSF has more explanatory power in cases where climate action is synergetic and entails co-benefits for other economic, social or sectoral goals, i.e., for what Hall (1993) considers as first and second order policy changes. These types of policy changes do not involve a shift in policy paradigms, nor a change in the hierarchy of goals behind policy. Nevertheless, when there are tensions or trade-offs between climate goals and other dimensions of sustainable development, as highlighted by the recent emphasis on sustainable transitions and transformational change, it is necessary to move from one policy paradigm to another - i.e., third-order policy change, according to Hall (1993). And here power plays a larger role. The lack of insightful perspectives on the role of power in the MSF points to the need for complementing MSF with notions from other public policy frameworks. Indeed, relying on several frameworks can provide a more complete explanation of policy change and its drivers (Cairney, 2007). 
Secondly, the MSF is methodologically nationalist and so does not explicitly consider the role of multilevel governance structures, such as the influence of global climate policy negotiations occurring under the umbrella of the UNFCCC, in national policy processes. Therefore, it would be relevant to expand the MSF to account for the potential impact of such external processes. In this regard, one could improve the MSF for the analysis of CPI in developing countries by incorporating concepts from development studies to analyse the role of foreign donors and development cooperation organizations as policy entrepreneurs or as enablers of policy entrepreneurs. This type of actor can influence the problem stream by providing technical assistance and other resources to strengthen monitoring systems, generate indicators and develop studies that decision-makers can use to demonstrate that there is indeed a problem and to assess its magnitude. Non-national actors can also be active in the policy stream by providing technical assistance and other resources for civil servants or think tanks to generate policy proposals. Furthermore, it would be interesting to analyse their potential effect on the political stream given that they can provide resources for some governments in the global South.

Thirdly, the MSF was developed based on the federal policy-making system of the United States, which involves some limitations regarding its application in other political contexts. In particular, the plurality of actors with relevant roles in agenda setting may vary, depending on the degree of fragmentation of different political systems or other characteristics (Page, 2006). Finally, the MSF does not consider the policy implementation and policy evaluation stages and we can therefore only use it to explain agenda setting and the specification of alternatives from which decision makers make policy choices. Other approaches, such as the improved "weaving" model (Howlett et al., 2016) can usefully complement the analysis of agenda setting and specification of alternatives for CPI.

This article has presented an appraisal of the suitability of the MSF to study CPI in countries in the global South based on documentary analysis. We acknowledge the limitations of this methodology: 
We relied on the analysis of documents from multi-country programs in order to have a broad coverage of data that could help contextualise CPI in developing countries, yet this implied a tradeoff between coverage and in-depth analysis of cases of CPI at country-level.

The assessment of the value of the MSF for CPI can be enhanced by applying it systematically to national case studies of CPI in different contexts. Different political systems, public policy making styles, and other socio-economic and cultural conditions may result in a different formation process of the policy windows for CPI. Thus, analysing this process in different settings will allow a clearer identification of the shortcomings of the MSF and shed light on complementary concepts from other public policy frameworks, or from other fields such as international relations or development studies, that can be used together with MSF to analyse CPI. So while this paper has shown that Kingdon's model is an appropriate analytical starting point for understanding CPI, future research should explore how the MSF can be further validated and combined with other approaches in the quest to better understand the challenges and processes of integrating climate action into policies that steer developing countries towards a sustainable development pathway.

\section{References}

Adelle, C., \& Russel, D. (2013). Climate policy integration: A case of deja vu? Environmental policy and governance, 1-12.

Ahmad, I. (2009, March). Climate Policy Integration: Towards Operationalization. Retrieved March 4th, 2007, from United Nations. Department of economic and social affairs: http://www.un.org/esa/desa/papers/2009/wp73_2009.pdf 
Ayers, J., Huq, S., Wright, H., Faisal, A., \& Hussain, S. (2014). Mainstreaming climate change adaptation into development in Bangladesh. Climate and development, 293-305. doi:10.1080/17565529.2014.977761

Beg, N., Morlot, J., Davidson, O., Afrone-Okesse, Y., Tyani, L., Denton, F., . . Rahman, A. (2002). Linkages between climate change and sustainable development. Climate policy, 129-144.

Béland, D. (2009). Ideas, institutions and policy change. Journal of European Public Policy, 701718.

Benson, E., Forbes, A., Korkeakoski, M., Latif, R., \& Lham, D. (2014). Environment and climate mainstreaming: challenges and successes. Development in practice, 605-614. doi:10.1080/09614524.2014.911819

Bocquillon, P. (2015). (De-)Constructing coherence? Strategic entrepreneurs, policy frames and the integration of climate and energy policies in the European Union. Environmental policy and governance, 339-349.

Brunner, S. (2008). Understanding policy change: Multiple streams and emissions trading in Germany. Global Environmental Change, 18, 501-507. doi:10.1016/j.gloenvcha.2008.05.003

Butler, J., Suadnya, W., Yanuartati, Y., Meharg, S., Wise, R., Sutaryono, Y., \& Duggan, K. (2016). Priming adaptation pathways through adaptive co-management: Design and evaluation for developing countries. Climate Risk Management, 12, 1-16. doi:10.1016/j.crm.2016.01.001

Cairney, P., 2007. A multiple lenses approach to policy change: the case of tobacco 
policy in the UK. British Politics 2, 45-68.

Campbell, J. (1998). Institutional analysis and the role of ideas in political economy. Theory and society, 377-409.

Carter, N., \& Jacobs, M. (2014). Explaining radical policy change: the case of climate change and energy policy under the British labour government 2006-10. Public Administration, 92(1), 125-141. doi:10.1111/padm.12046

Conway, D., \& Schipper, L. (2011). Adaptation to climate change in Africa: Challenges and opportunities identified from Ethiopia. Global Environmental Change, 227-237. doi:10.1016/j.gloenvcha.2010.07.013

Dalal-Clayton, B., \& Bass, S. (2009). The challenges of environmental mainstreaming. London: IIED.

Denton, F., Wilbanks, T., Abeysinghe, A., Burton, I., Gao, Q., Lemos, M., .. . Warner, K. (2014). Climate resilient pathways: adaptation, mitigation and sustainable development. In Climate change 2014: Impacts, adaptation and vulnerability. Part A: Global and Sectoral Aspects. Contribution of work group II to the fifth assessment report of the Intergovernmental Panel on Climate Change (pp. 1101-1131). Cambridge, UK \& New York, USA: Cambridge University Press.

Di Gregorio, M., Nurrochmat, D. R., Paavola, J., Sari, I. M., Fatorelli, L., Pramova, E., .. . Kusumadewi, S. D. (2017). Climate policy integration in the land use sector: Mitigation, adaptation and sustainable development linkages. Environmental Science \& Policy, 35-43. doi:10.1016/j.envsci.2016.11.004 
Dupont, C., \& Oberthur, S. (2012). Insufficient climate policy integration in EU energy policy: the importance of the long term perspective. Journal of contemporary European research, 8(2), $228-247$.

European Commission. (2012b, September 3). GCCA Global Learning Event 2012. Mainstreaming climate change into national development planning: GCCA experience. Retrieved February 19 2018, from Global Climate Change Alliance+:

http://www.gcca.eu/sites/default/files/gcca_tp_mainstreaming_final_2012-09-03_0.pdf

European Commission. (2012c). Mainstreaming climate change. Retrieved February 16, 2018, from Global Climate Change Alliance+: http://www.gcca.eu/about-the-gcca/innovative-andeffective-approaches/mainstreaming-climate-change

European Commission. (2013a, December). From Integrated Climate Strategies to Climate Finance Efectiveness: Experiences from the Global Climate Change Alliance. doi:10.2841/22430

European Commission. (2013b, October). GCCA Global Policy Event 2013. Summary of key political and technical conclusions. Retrieved April 3, 2018, from Global Climate Change Alliance+:

http://www.gcca.eu/sites/default/files/technical_and_political_conclusions_final_2013-1018.pdf

Fleurbaey, M., Kartha, S., Bolwig, S., Chee, Y., Chen, Y., Corbera, E., . . Sagar, A. (2014). Sustainable development and equity. In O. Edenhofer, R. Pichs-Madruga, Y. Sokona, E. Farahani, S. Kadner, K. Seyboth, .. . J. Minx, Climate Change 2014: Mitigation of climate change. Contribution of working group III to the fifth assessment report of the Intergovernmental Panel on Climate Change (pp. 283-350). Cambridge \& New York: Cambridge University Press. 
Geels, F., Berkhout, F. \& van Vuuren, D. Bridging analytical approaches for low-carbon transitions. Nature Clim Change 6, 576-583 (2016) doi:10.1038/nclimate2980

Greer, S. (2015). John W. Kingdon, Agendas, Alternatives and Public Policies. In S. Balla, M. Lodge, \& E. Page, The Oxford Handbook of Classics in Public Policy and Administration (pp. 417-432). Oxford: OUP Oxford.

Gupta, J. (2010). Mainstreaming climate change: a theoretical exploration. In J. Gupta, \& N. Van der Grijp, Mainstreaming climate change in development cooperation. Theory, practice and implications for the European Union (pp. 67-96). Cambridge: Cambridge University Press.

Hall, P.A., 1993. Policy paradigms, social learning, and the state: the case of economic policymaking in Britain. Comp. Polit. 275-296.

Hermansen, E. (2015). Policy window entrepreneurship: the backstage of the world's largest REDD+ initiative. Environmental Politics, 932-950. doi:10.1080/09644016.2015.1063887

Howlett, M. (1998). Predictable and Unpredictable Policy Windows: Institutional and Exogenous Correlates of Canadian Federal Agenda Setting. Canadian Journal of Political Science, $31(3), 495-524$.

Howlett, M., McConnell, A., \& Perl, A. (2016). Weaving the fabric of public policies: comparing and integrating contemporary frameworks for the study of policy processes. Journal of comparative policy analysis: research and practice, 273-289.

Humalisto, N. (2015). Knowledge in Climate Policy Integration: How nongovernmental organizations re-frame the sciences of indirect land-use changes for policymakers. Environmental policy and governance, 25, 412-423. doi:10.1002/eet.1692 
INGC. (2009, May). Study on the Impact of Climate Change on Disaster Risk in Mozambique: Synthesis Report. Retrieved from UNDP - Mozambique: http://www.mz.undp.org/content/dam/mozambique/docs/Environment_and_Energy/INGC_ Synthesis_Report_ClimateChange_Low-1.pdf

IRENA. (2017, November). Untapped potential for climate action: Renewable energy in Nationally Determined Contributions. Retrieved February 6, 2018, from IRENA: http://www.irena.org//media/Files/IRENA/Agency/Publication/2017/Nov/IRENA_Untapped_potential_NDCs_20 17.pdf

Keskitalo, C., Westerhoff, L., \& Juhola, S. (2012). Agenda-setting on the environment: the development of climate change adaptation as an issue in European states. Environmental Policy and Governance, 381-394. doi:10.1002/eet.1579

Kettner, C., Kletzan-Slamanig, D., \& Koppl, A. (2015). Climate policy integration: evidence on coherence in EU Policies. In L. Kreiser, M. Skou Andersen, B. Egelund Olsen, S. Speck, J. Milne, \& H. Ashiabor, Environmental pricing. Studies in Policy Choices and Interactions (pp. 3-16). Cheltenham, UK: Edward Elgar Publishing.

Kingdon, J. (2014). Agendas, alternatives, and public policies (Second ed.). Essex: Pearson Education Limited.

Kok, M., \& de Coninck, H. (2007). Widening the scope of policies to address climate change: directions for mainstreaming. Environmental Science and Policy, 587-599. doi:10.1016/j.envsci.2007.07.003 
Lafferty, W., \& Hovden, E. (2003). Environmental policy integration: towards an analytical framework. Environmental politics, 12(3), 1-22. doi:10.1080/09644010412331308254

Löhr, E., Perera, N., Hill, N., Bongardt, D., \& Eichhorst, U. (2017). Transport in NDCs - Lessons learnt from case studies of rapidly motorising countries. Bonn: GIZ.

Lorenzoni, I., \& Benson, D. (2014). Radical institutional change in environmental governance: Explaining the origins of the UK Climate Change Act 2008 through discursive and streams perspectives. Global Environmental Change, 29, 10-21. doi:10.1016/j.gloenvcha.2014.07.011

Mickwitz, P., Aix, F., Beck, S., Carss, D., Ferrand, N., Gorg, C., . . . van Bommel, S. (2009, March). Climate policy integration, coherence and governance. PEER Report No. 2. Retrieved from Partnership for European Environmental Research: http://www.peer.eu/fileadmin/user_upload/publications/PEER_Report2.pdf

Nilsson, M., \& Nilsson, L. (2005). Towards climate policy integration in the EU: evolving dilemmas and opportunities. Climate policy, 5(3), 363-376. doi:10.1080/14693062.2005.9685563

Nilsson, M., \& Persson, A. (2003). Framework for analysing environmental policy integration. Journal of Environmental Policy and Planning, 5(4), 333-359. doi:10.1080/1523908032000171648

Olhoff, A., \& Schaer, C. (2009). Screening Tools and Guidelines to Support the Mainstreaming of Climate Change Adaptation into Development Assistance - A stocktaking report. New York: UNDP. 
Olsson, L., Opondo, M., Tschaker, P., Agrawal, A., Eriksen, S., Ma, S., . . Sakielden, S. (2014). Livelihoods and poverty. In Climate Change 2014: Impacts, Adaptation and Vulnerability. Part A: Global and Sectoral Aspects. Contribution of Group II to the Fifth Assessment Report of the IPCC (pp. 793-832). Cambridge, UK and New York, USA: Cambridge University Press.

Persson, A., Eckerberg, K., \& Nilsson, M. (2016). Institutionalization or wither away? Twenty-five years of environmental policy integration under shifting governance models in Sweden. Environment and Planning C: Government and Policy, 478-495. doi:10.1177/0263774X15614726

Pilato, G., Sallu, S., \& Gaworek-Michalczenia, M. (2018). Assessing the integration of climate change and development strategies at local levels: insights from Muheza District, Tanzania. Sustainability, 1-25. doi:10.3390/su10010174

Rietig, K. (2013). Sustainable Climate Policy Integration in the European Union. Environmental Policy and Governance, 23, 297-310. doi:10.1002/eet.1616

Rietig, K., \& Perkins, R. (2017). Does learning matter for policy outcomes? The case of integrating climate finance into the EU budget. Journal of European Public Policy. doi:10.1080/13501763.2016.1270345

Runhaar, H. (2016). Tools for integrating environmental objectives into policy and practice: What works where? Environmental Impact Assessment Review, 1-9. doi:10.1016/j.eiar.2016.03.003 
Runhaar, H., Driessen, P., \& Uittenbroek, C. (2014). Towards a systematic framework for the analysis of Environmental Policy Integration. Environmental Policy and Governance, 24, 233-246. doi:10.1002/eet.1647

Russel, D., den Uyl, R., \& de Vito, L. (2018). Understanding policy integration in the EU - Insights from a multi-level lens on climate adaptation and the EU's coastal and marine policy. Environmental Science and Policy, 44-51. doi:10.1016/j.envsci.2017.12.009

Saito, N. (2013). Mainstreaming climate change adaptation in least developed countries in South and Southeast Asia. Mitigation and Adaption Strategies for Global Change, 825-849. doi:10.1007/s11027-012-9392-4

Saldana, J. (2009). The coding manual for qualitative researchers. London: SAGE Publications.

Schout, A., \& Jordan, A. (2008). Administrative instruments. In A. Jordan, \& A. Lenschow, Innovation in Environmental Policy? Integrating the Environment for Sustainability (pp. 4969). Cheltenham, UK: Edward Elgar Publishing Limited.

Scobie, M. (2016). Policy coherence in climate governance in Caribbean Small Island Developing States. Environmental Science \& Policy, 16-28. doi:10.1016/j.envsci.2015.12.008

Sovacool, B., Martiskainen, M., Hook, A. \& Baker, L. Beyond cost and carbon: The multidimensional co-benefits of low carbon transitions in Europe, Ecological Economics, Volume 169, 2020, https://doi.org/10.1016/j.ecolecon.2019.106529. 
Steuner, R., \& Clar, C. (2015). Is decentralisation always good for climate change mitigation? How federalism has complicated the greening of building policies in Austria? Policy Sci, 85-107. doi:10.1007/s11077-014-9206-5

Storbjörk, S., Lähteenmäki-Smith, K., \& Hilding-Rydevik, T. (2009). Conflict or consensus: The Challenge of Integrating Environmental Sustainability into Regional Development Programming. European Journal of Spatial Development.

Storch, S., \& Winkel, G. (2013). Coupling climate change and forest policy: A multiple streams analysis of two German case studies. Forest policy and economics, 36, 14-26. doi:10.1016/j.forpol.2013.01.009

Strohmaier, R., Rioux, R., Seggel, A., Meybeck, A., Bernoux, M., Salvatore, M., . . Agostini, A. (2016). The agriculture sectors in the Intended Nationally Determined Contributions: Analysis. Rome: FAO. Retrieved February 6, 2018, from FAO: http://www.fao.org/3/ai5687e.pdf

Tosun, J., \& Lang, A. (2017). Policy integration: mapping the different concepts. Policy studies, 553-370. doi:10.1080/01442872.2017.1339239

Uittenbroek, C., Janssen-Jansen, L., Spit, T., Salet, W., \& Runhaar, H. (2014). Political commitment in organising municipal responses to climate adaptation: the dedicated approach versus the mainstreaming approach. Environmental Politics, 23(6), 1043-1063. doi:10.1080/09644016.2014.920563

UNDP-UNEP. (2009). Guidance note: Mainstreaming poverty-environment linkages into national development planning. Retrieved February 19, 2018, from UNDP-UNEP PovertyEnvironment Initiative: https://www.unpei.org/sites/default/files/publications/eng.pdf 
UNDP-UNEP. (2011). Mainstreaming climate change adaptation into development planning: a guide for practitioners. Retrieved February 19, 2018, from UNDP-UNEP PovertyEnvironment Initiative: http://www.unpei.org/knowledgeresources/publications/mainstreaming-climate-change-adaptation-into-developmentplanning-a-guide-for-practitioners-may-2011

UNDP-UNEP. (2015). About the Poverty-Environment Initiative. Retrieved February 6, 2018, from UNDP-UNEP Poverty-Environment initiative: http://www.unpei.org/about-the-povertyenvironment-initiative

UNDP-UNEP. (2016a, March 31). PEI Annual Progress Report 2015. Retrieved February 19, 2018, from UNDP-UNEP Poverty-Environment Initiative: http://www.unpei.org/sites/default/files/publications/AR\%202015\%20\%20technical\%20report.pdf

UNDP-UNEP. (2017b). Mainstreaming Environment and Climate for Poverty Reduction and Sustainable Development: The Interactive Handbook to Strengthen Planning and Budgeting Processes. Retrieved February 19, 2018, from UNDP-UNEP Poverty-Environment Initiative: http://www.unpei.org/knowledge-resources/publications/mainstreamingenvironment-and-climate-for-poverty-reduction-and-sustainable-development-theinteractive-handbook-to-strengthen-planning-and-budgeting-processes

UN Environment Programme, 2019. Emissions Gap Report 2019. https://www.unenvironment.org/resources/emissions-gap-report-2019

UNFCCC. (2002). Report of the Conference of the Parties on Its Seventh Session, held at Marrakech from 29 October to 10 November 2001. UNFCCC. 
UNFCCC. (2015). Paris Agreement. Retrieved June 7, 2017, from UNFCCC:

http://unfccc.int/files/essential_background/convention/application/pdf/english_paris_agree ment.pdf

UNFCCC. (2017, June 7). Paris Agreement - Status of ratification. Retrieved June 7, 2017, from UNFCCC: http://unfccc.int/paris_agreement/items/9444.php

Vasileiadou, E., \& Tuinstra, W. (2013). Stakeholder consultations: mainstreaming climate policy in the Energy Directorate? Environmental Politics, 22(3), 475-495. doi:10.1080/09644016.2012.717376

Visseren-Hamakers, I. (2014). Integrative environmental governance: enhancing governance in the era of synergies. Current Opinion in Environmental Sustainability, 136-143. doi:10.1016/j.cosust.2015.05.008

Wamsler, C., \& Pauleit, S. (2016). Making headway in climate policy mainstreaming and ecosystem-based adaptation: two pioneering countries, different pathways, one goal. Climatic Change, 71-87. doi:10.1007/s10584-016-1660-y 
Table 1. Types of policy windows and potential openers

\begin{tabular}{|c|c|c|c|}
\hline Stream & $\begin{array}{l}\text { Window } \\
\text { type }^{\dagger}\end{array}$ & Definition $^{\dagger}$ & Potential openers ${ }^{\ddagger}$ \\
\hline \multirow[t]{2}{*}{ Problems } & Random & $\begin{array}{l}\text { Random events or crises } \\
\text { open unpredictable } \\
\text { windows }\end{array}$ & $\begin{array}{l}\text { Focusing events } \\
\text { Indicators } \\
\text { Policy feedback }\end{array}$ \\
\hline & Spillover & $\begin{array}{l}\text { Related issues are drawn } \\
\text { into an already open } \\
\text { window }\end{array}$ & $\begin{array}{l}\text { High-profile issues, to which own problems } \\
\text { can be attached }\end{array}$ \\
\hline \multirow[t]{2}{*}{ Political } & Routine & $\begin{array}{l}\text { Institutionalized } \\
\text { procedural events dictate } \\
\text { predictable window } \\
\text { openings }\end{array}$ & $\begin{array}{l}\text { Institutional procedures } \\
\text { Political-administrative turnovers }\end{array}$ \\
\hline & Discretionary & $\begin{array}{l}\text { The behavior of } \\
\text { individual political actors } \\
\text { lead to less predictable } \\
\text { window openings }\end{array}$ & $\begin{array}{l}\text { Discrete steps of influential policy makers } \\
\text { Political campaigns }\end{array}$ \\
\hline
\end{tabular}

Note: ${ }^{\dagger}$ Source: (Howlett, 1998, p. 500) ${ }^{\ddagger}$ Source: (Storch \& Winkel, 2013, p. 16) 


\section{Table 2. Analysis of two climate mainstreaming initiatives using elements from the policy windows framework ${ }^{1}$}

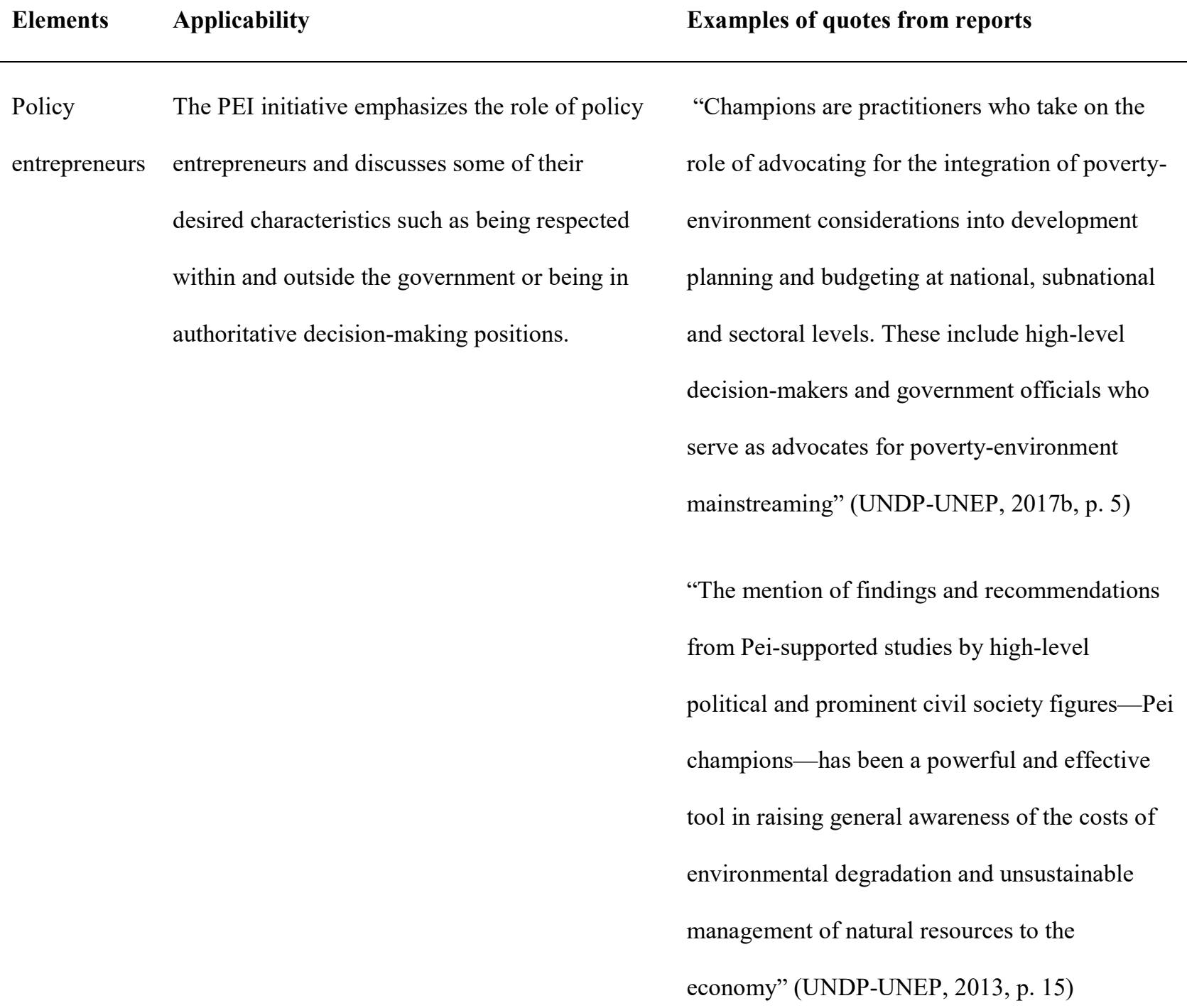

Problem Some identified lessons learned from the PEI stream and the GCCA initiatives relate to the potential to use spillover windows by centering mainstreaming on high-profile issues in the countries.
"The focus on high-profile public policy issues can instill motivation to understand mainstreaming. Examples include mining in Mongolia and the Philippines, climate vulnerability and disaster risk reduction in 
Examples of quotes from reports

Bangladesh and Nepal, and food security in some African countries" (UNDP-UNEP, 2017b, p.15)

"For example, where food security is a priority development issue and/or poor farmers are already suffering from current climate variability, mainstreaming can focus on integrating climate change adaptation concerns in the national agricultural strategy and/or budget, taking into account the government calendar for these various processes." (UNDPUNEP, 2009, p. 20)

"In Mauritius and Seychelles, for example, national development strategies include objectives in terms of reduced dependence on imported fuels and increased energy security; this provides a rationale for mainstreaming climate change mitigation (through increased use of renewable energies and energy efficiency) into the energy sector" (European Commission, 2012b, p.8)

Kingdon (2014) suggests that attention to problems can be driven by indicators, which can be routinely monitored, like the monitoring of federal expenditures, or studies conducted on a particular problem at a given point in time. In
"In Mozambique, environmental and climate change issues have been rising on the political agenda, based on evidence of impacts on development, and on publications such as the 2009 'Study on the Impact of Climate Change on 
this sense, both the PEI and GCCA highlight the use of cost-benefit studies, expenditure reviews and studies that quantify the value of natural and social capital to better communicate the magnitude of the problem to decision-makers.

Both, the PEI and GCCA also highlight the opening of random windows from focusing events. Focusing events such as weather events like floods or droughts can reveal current and potential future harms thus opening windows to address the policy failures revealed by such events.
Disaster Risk in Mozambique'. Rising awareness

of the country's vulnerability has led the

government to support the mainstreaming of adaptation measures and environmental sustainability in economic planning." (European Commission, 2012b, p.14)

"Building on work undertaken in 2014 including a report on environment and information tools-Mauritania's Ministry of Environment, with technical advice from PEI, established a sustainable development database in 2015. The database includes information on poverty-environment-relevant indicators such as access to clean energy, water and sanitation and the state of the environment. The data collected in the database are now available on the ministry's website for sector institutions and their partners to consult and use in monitoring and informing sector policy and planning processes in support of sustainable development.”(UNDP-UNEP, 2016a, p. 18)

"The flood of 2000 caused damage estimated at approximately $\$ 145$ million. As a result, Cambodia has prioritized specific coastal zone and disaster management measures, and additional sector adaptations. These priorities 
Examples of quotes from reports

have been effectively integrated into Cambodia's

PRSP (2003), which includes a significant

component devoted to disaster risk management"

(UNDP-UNEP, 2011, p. 52)

Raising the importance of climate change and disaster risk reduction in the political agenda can be achieved by producing credible evidence of the loss and damage induced by climate change, by using economic analysis to make the case for action and by using the momentum triggered by major climatic disasters to prompt action. (European Commission, 2013a, p. 14)

The policy windows framework (Kingdon J. W., "The use of performance measures can be a 2014) suggests that the problem stream can be challenge. Often, no proper indicators are in influenced as well by feedback from current place to monitor climate change impacts and programs. In line with this, the GCCA initiative vulnerability and/or the effectiveness of devoted resources to implement systems that adaptation and mitigation measures, and the allowed monitoring the performance of the onset of GCCA budget support stimulates their climate measures being implemented in order to design” (European Commission, 2014, p. 50) generate feedback for policy-makers.

Politics Evidence from the PEI emphasizes the need to stream leverage on routine policy windows opening from the political stream.
"Timing, particularly when seeking to mainstream long-range climate change issues, is important. It would be counterproductive to present evidence and justifications aimed at 
Examples of quotes from reports

suggesting that national development objectives should reference climate change resilience when the central coordinating unit and sector working groups have already formulated the key development objectives of the next five-year

Evidence from PEI implementation in Kenya and Malawi also shows the opening of windows in the political stream arising from a change in administration and from behavior of individual political actors.

Lessons learned from the GCCA initiative show the need to identify windows that open predictably from scheduled institutional procedures. In the cases of Bhutan and Samoa, GCCA activities were synchronized with the government's calendar in order to influence the 11th Five year Plan and the Water for Life sector plan respectively. development plan.” (UNDP-UNEP, 2017b, p.

44)

"Since 2007, PEI has been supporting the process of developing Kenya's first-ever national environmental policy; this effort was stalled until 2012, when it was revitalized by a new minister" (UNDP-UNEP, 2013, p. 43)

"In Malawi, for example, it was not until three years after the country's NAPA was first published that a presidential intervention to relaunch the document succeeded in sparking cross-ministry interest in adaptation" (UNDP-

UNEP, 2011, p. 34)

"This is not to say that climate change mainstreaming can only take place during these privileged windows of opportunity. However, while policies, strategies, plans and the legal and regulatory framework governing climate change can be reviewed at any time to check compatibility with and/or integration of climaterelated considerations, a review coinciding with 
Examples of quotes from reports

the national planning process have more chances

of quickly leading to effective changes and

results.” (European Commission, 2012b, p. 16)

Policy The results from both the PEI and the GCCA

stream

point at the need for proposals to fit with

dominant values of policy community members

and increase the public's and the politician's

receptivity by framing the proposals with an

economic lens. By framing the proposals with an

economic lens and providing evidence about the

economic benefits of mainstreaming, an

argument is built for the budget feasibility of the proposed actions.
"Tailor the language of these communications to the intended audience and their interests.

Generally, economists and development planners have relatively little familiarity with environmental terminology and jargon. Express findings and recommendations in economic terms that can be more easily assimilated by those driving the national development planning process” (UNDP-UNEP, 2017b, p. 46)

"The study showed that the yearly economic loss due to environmental degradation and the inefficient use of natural resources in Mozambique is $17 \%$ of GDP and that the estimated cost to remediate these damages is $9 \%$ of GDP. Making use of this evidence, the ministry is advocating for increased budget allocations to implement poverty-environment objectives integrated in national and provincial development plans” (UNDP-UNEP, 2013, p. 37)

"Tools such as feasibility studies, vulnerability assessment and economic analysis will also be used to enhance the body of evidence on which 


\section{Examples of quotes from reports}

Both initiatives also highlight the need for

to base strategic choices and planning decisions"

proposals to be technically and budgetary

(European Commission, 2012b, p. 9)

feasible. In terms of budgetary feasibility, they

"In Samoa, the EU has supported the water

additionally stress the importance of supporting

sector through sector budget support since 2010;

improved access to climate finance to enhance

this has helped integrate water sector planning,

resource allocation for climate change priorities.

budgeting and institutional processes into the

government's wider planning systems and

processes and develop planning and

implementation capacity. This experience made

it easier for the GCCA to opt for the budget

support modality..." (European Commission,

2014, p. 37)

[In Nepal] "The climate budget code also allows

for the analysis of climate programs in relation

to other priority indicators related to poverty

reduction and gender equality. The national

Planning commission's planning guidelines have

further incorporated the directive that makes

coding of each development programme for

climate relevance mandatory in the national

budgetary process. To this end, the ministry of

finance added an annex to the national budget

guidelines called the 'red book' which

demonstrates the government's commitment to

improving its financial system and increasing its

transparency and accountability in complying 
with requirements for accessing global climate funds." (UNDP-UNEP, 2013, p. 31)

Policy communities and larger publics need to be "softened up" and the way needs to be paved to be ready when a policy window opens by getting them used to new ideas and building acceptance for proposals. In this regard, both the GCCA and PEI highlight the need to build awareness and soften-up the system before moving to mainstreaming implementation.
"Outreach and involvement of a wide range of stakeholders are also critical to generate public support: buy-in should be sought not just from political leaders and central government, but also from local government and non-state actors" (European Commission, 2013b, p. 15)

“The preliminary assessments conducted should provide a solid basis on which to build messages and awareness-raising on poverty-environment issues. Findings from these assessments should be disseminated broadly within the government, including to the head of state's office, political parties and the parliament, the judicial system, finance and planning bodies, environmental institutions, sector and subnational bodies, and the national statistics office. National workshops or consultations can be held to raise awareness among various audiences, including government, civil society, academia, business and industry, the media, and the general public" (UNDP-

UNEP, 2017b, p. 31)

Notes: ${ }^{1}$ The initiatives analyzed in this table are the Poverty-Environment Initiative of UNDP and UNEP, and the Mainstreaming Climate Change into National Development Planning initiative of the 
Global Climate Change Alliance established by the European Commission based on the documents listed in Appendix 3. 